\title{
Analysis of Influencing Factors on Public Perception in \\ Contaminated Site Management: Simulation by Structural Equation Modeling at Four Sites in China
}

Xiaonuo Li ${ }^{1}$, Weiping Chen ${ }^{1, *}$, Andrew B. Cundy ${ }^{2, *}$ Andrew C. Chang ${ }^{3}$, Wentao Jiao ${ }^{1}$

1 State Key Laboratory of Urban and Regional Ecology. Research Center for Eco-Environmental Sciences. Chinese Academy of Sciences. Beijing 100085. China. lixiaonuo1988@163.com, wpchen@rcees.ac.cn,wtjiao@rcees.ac.cn

${ }^{2}$ Ocean and Earth Science, University of Southampton, Southampton, SO14 3ZH, U.K. A.Cundy@soton.ac.uk

${ }^{3}$ Department of Environmental Sciences. University of California. Riverside. CA 92521. United States. andrew.chang@ucr.edu

${ }^{*}$ Corresponding authors.

E-mail: wpchen@rcees.ac.cn Tel.: +86 010 62843981. (Weiping Chen)

E-mail: A.Cundy@soton.ac.uk Tel.: +44 2380 596179. (Andrew B. Cundy)

Published as a research article in:

Journal of Environmental Management 210 (2018) pp 299-306 
Abstract: Public perception towards contaminated site management, a not readily quantifiable latent parameter, was linked through structural equation modeling in this paper to 22 measurable/observable manifest variables associated with the extent of information dissemination and public knowledge of soil pollution, attitude towards remediation policies, and participation in risk mitigation processes. Data obtained through a survey of 412 community residents at four remediation sites in China were employed in the model validation. The outcomes showed that public perception towards contaminated site management might be explained through selected measurable parameters in five categories, namely information disclosure, knowledge of soil pollution, expectations of remediation and redevelopment outcomes, public participation, and site policy, along with their interactions. Among these, information dissemination and attitude towards management policies exhibited significant influence in promoting positive public perception. Based on these examples, responsible agencies therefore should focus on public accessibility to reliable information, and encourage public inputs into policies for contaminated site management, in order to gain public confidence during remediation and regeneration projects.

Keywords: Questionnaire interview; Structural equation modeling; Public perception; Contaminated site; Remediation; China. 


\section{Introduction}

Contaminated sites need to be restored or managed in a sustainable manner which minimizes human health and eco-environmental risks, and (ideally) creates social, environmental and economic gains from investment (Bardos et al., 2016; Hou et al., 2014a). Risk management can be accomplished through a combination of legal mechanisms and/or setting policies, guidelines and strategies (Cundy et al., 2013; Ferguson, 1999; Jin, 2012; Johansson et al., 2011; Rodrigues et al., 2009a, 2009b; Sousa, 2001; Swartjes et al., 2012; Thornton et al., 2007), employing effective remediation technologies or site management strategies (Blanc et al., 2004; Busset et al., 2012; Cadotte et al., 2007; Cappuyns, 2013; CLARINET, 2002; Hou et al., 2014b; Smith, 2010; USEPA, 2008; Volkwein et al., 1999), and engaging with the public / local stakeholders to manage site use, limit exposure pathways and to more effectively deliver remediation or management interventions (Alberini et al., 2007; Eiser, 2009; Feldman and Hanahan, 1996; Grasmück and Scholz, 2005; Scholz and Siegrist, 2010; Tonin et al., 2011; Vandermoere, 2008). In relation to the latter, restoration scheme success (in terms of effective risk management, and maximization of social, environmental and economic gains) depends not only on how the responsible parties implement remediation or management plans, but also on the participation and support of local residents whose wellbeing hinges upon the final outcomes (Li and Tan, 2012). A number of international groups and projects have argued that effective engagement with local stakeholders is key in reducing remediation project risks, including failure to gain acceptance and delays due to 
antagonistic relationships, and also as a means of reducing project management costs and timescale (Cappuyns, 2016; Cundy et al., 2013; RESCUE, 2005; REVIT, 2007). Such engagement requires early consultation with local groups and the wider public to ensure that views are identified, assessed and incorporated (where necessary) into site master planning early on, or upstream, in the development process (SU BRIM Project, 2008), and to ensure wider social, environmental and economic benefits are fully realized (Cundy et al., 2013). Understanding public perception toward the local site, and to contaminated site management more generally, is essential in this process (e.g. Harclerode et al., 2016). Many subjective / emotional perceptions however are not directly measurable or easily collected, and so may not be included effectively in the planning and development process.

Application of structural equation modeling may address this problem. Structural equation modeling is founded on statistical methods that test validities of a theoretically/conceptually-conceived model linking qualitative perceptive responses such as public perception to readily definable and measurable parameters. The method has been utilized to answer research questions in psychology (Carpita and Ciavolino, 2014; Ko and Stewart, 2002; Trzeciakowski et at., 2014), environmental sciences (e.g. Eisenhauer et al., 2015; Santibáñez-Andrade et al., 2015; Levêque and Burns, 2017) and marketing (Subramanian et al., 2014). For example, in the environmental sciences, Eisenhauer et al. 2015 reviewed the application of SEM in the general ecology (and soil ecology) literature, modeled multivariate relationships between hypotheses and observed data, tested mediation of multiple variables, and gave examples of the 
potential use of SEM in allowing a shift from describing ecological patterns to gaining an improved mechanistic understanding of ecological variables. Santibanez-Andrade et al. 2015 used SEM to evaluate the direct and indirect causes of degradation in the forests of the Magdalena river basin of Mexico City, by linking environmental indicators on the structure, composition and function of the ecosystem. Few studies however have been carried out in the field of public perceptions toward site remediation practices, although Hou et al. (2014a) employed factor analysis (FA) in structural equation modeling (SEM) to identify influences of qualitative latent factors such as sustainability considerations, benefiting and impeding institutional forces, and stakeholders' influence, in contaminated land remediation.

In our research, structural equation modeling is applied to delineate how the public perception of actions taken during contaminated site mitigation is driven by latent exploratory variables, using brownfield redevelopment sites in China as a test case. In turn, each latent variable is represented in a measurement sub-model consisting of readily measurable factors. Data were collected through questionnaire surveys conducted at four active remediation sites in China, and are used to validate the model. Public perception is represented by multivariate relationships among exploratory variables including the extent of information disclosure, outreach and education, the degree of public participation, satisfaction with the outcomes of remediation and redevelopment, understanding of site remediation policies and management, and knowledge of soil pollution. 


\section{Methodology}

\subsection{Exploratory Variables}

A four-part questionnaire was designed to measure 22 factors (Table 1) which have been previously argued to characterize public perceptions towards contaminated site management (Cundy et al., 2013; Eiser et al., 2009; Feldman and Hanahan, 1996; Grasmück and Scholz, 2005; Greenberg and Lewis, 2000; Li and Tan, 2012; Scholz and Siegrist, 2010; Tonin et al., 2011; Vandermoere, 2008). The first part of the questionnaire collected socio-demographic information on the subjects including gender, age, education, occupation, household size, income, and duration of residence. The second part encompassed factors characterizing exploratory variables related to the subjects' knowledge of soil pollution at the contaminated site (SP), namely understanding of soil pollution (X1), hazards of pollutants (X2), severity (X3) and causes (X4) of pollution, and willingness for relocation (X5 - symbols inside the parentheses denote the abbreviated notation for each factor in the SEM). The third part included 11 questions with choices of yes/no/neutral answers, measuring:

(1) Factors characterizing exploratory variables related to subjects' satisfaction with authorities’ information disclosure (ID), ranging from X6 to X10 (Table 1);

(2) Factors characterizing exploratory variables related to public outreach and education (OE), ranging from X11 to X13 (Table 1);

(3) Factors characterizing exploratory variables related to public participation, ranging from X14 to X16 (Table 1).

The final part of the questionnaire examined factors characterizing exploratory 
variables related to:

(1) Subjects' familiarity with management policies of contaminated site (PS), including factors characterizing whether or not to solicit public insight (X17), willingness to learn about policies (X18), and satisfaction with policies in damage compensation, dissemination of information and sustainable remediation (X19);

(2) Public desire to support the project (RE), including opinions on willingness to pay for contaminated site remediation (X20), satisfaction with alternative reuse possibilities (e.g., housing, recreation, agriculture) (X21), and willingness to purchase houses built on remediated sites (X22).

Table 1 Factors included in the survey questionnaire

\begin{tabular}{|c|c|c|}
\hline Module & Factor & Definition \\
\hline \multirow[t]{5}{*}{ Pollution (SP) } & $\mathrm{X} 1$ & Understanding of soil pollution \\
\hline & $\mathrm{X} 2$ & Soil pollution hazards \\
\hline & X3 & Severity of soil pollution \\
\hline & $\mathrm{X} 4$ & Causes of soil pollution \\
\hline & $\mathrm{X} 5$ & Willingness to relocate \\
\hline \multirow[t]{5}{*}{ Disclosure (ID) } & X6 & Information disclosure \\
\hline & $\mathrm{X} 7$ & Attention to information disclosure \\
\hline & $\mathrm{X} 8$ & Extent of information disclosure \\
\hline & X9 & Timeliness of information disclosure \\
\hline & $\mathrm{X} 10$ & Credibility of information disclosure \\
\hline \multirow[t]{3}{*}{ Publicity (OE) } & $\mathrm{X} 11$ & Attention to publicity \\
\hline & $\mathrm{X} 12$ & Extent of knowledge outreach \\
\hline & $\mathrm{X} 13$ & Satisfaction with publicity \\
\hline \multirow[t]{3}{*}{ Participation (PP) } & $\mathrm{X} 14$ & Soliciting opinions or not \\
\hline & $\mathrm{X} 15$ & Attention to public participation \\
\hline & X16 & Satisfaction with public participation \\
\hline \multirow[t]{2}{*}{ Policy (PS) } & $\mathrm{X} 17$ & Familiarity with policies \\
\hline & X18 & Satisfaction with policies \\
\hline
\end{tabular}




\begin{tabular}{lll} 
& X19 & Willingness to learn about policies \\
Redevelopment (RE) & X20 & Willingness to pay for remediation \\
& X21 & Satisfaction with redevelopment \\
X22 & Willingness to pay for real estate \\
\hline
\end{tabular}

\subsection{Survey Protocols}

The four sites surveyed were a coking plant in Beijing, a pesticide factory in Hangzhou, a nitrogen fertilizer factory in Guangzhou, and the Disney development project in Shanghai (all in China). All sites were undergoing active redevelopment or remediation at the time of the survey (Table 2).

Table 2 Details of surveyed sites

\begin{tabular}{|c|c|c|c|c|}
\hline Site & $\begin{array}{l}\text { Major } \\
\text { contaminants }\end{array}$ & $\begin{array}{l}\text { Remediation } \\
\text { measures }\end{array}$ & $\begin{array}{l}\text { Remediation } \\
\text { size / volume }\end{array}$ & Site end-use \\
\hline $\begin{array}{l}\text { Coking plant, } \\
\text { Beijing }\end{array}$ & $\begin{array}{l}\text { PAHs, } \\
\text { benzene }\end{array}$ & $\begin{array}{l}\text { In-situ, thermal } \\
\text { desorption }\end{array}$ & $342,000 \mathrm{~m}^{2}$ & Residence \\
\hline $\begin{array}{l}\text { Pesticide factory, } \\
\text { Hangzhou }\end{array}$ & $\begin{array}{l}\text { VOC, SVOC, } \\
\text { POPs }\end{array}$ & $\begin{array}{l}\text { In-situ, soil vapor } \\
\text { extraction, thermal } \\
\text { desorption }\end{array}$ & $50,000 \mathrm{~m}^{2}$ & Undeveloped \\
\hline $\begin{array}{l}\text { Fertilizer factory, } \\
\text { Guangzhou }\end{array}$ & VOC & $\begin{array}{l}\text { Ex-situ, burning in } \\
\text { cement kiln }\end{array}$ & $9,000 \mathrm{~m}^{3}$ & Residence \\
\hline $\begin{array}{l}\text { Disney project, } \\
\text { Shanghai }\end{array}$ & $\begin{array}{l}\text { VOC, Heavy } \\
\text { Metal }\end{array}$ & $\begin{array}{l}\text { Advanced oxidation } \\
\text { process, stabilization, } \\
\text { bio-reactors }\end{array}$ & $40,000 \mathrm{~m}^{3}$ & Entertainment \\
\hline
\end{tabular}

Those residents living in a radius of $200 \mathrm{~m}$ from each contaminated site, following findings from our earlier surveys ( $\mathrm{Li}$ et al. 2016), were more vocal about, had stronger opinions toward, and paid more attention to, the progress of the remediation projects. Their perceptions would provide the most critical information 
for establishing the structural equation modeling. At each location, 110 subjects residing within the $200 \mathrm{~m}$ radius were randomly selected. In total, 412 sets of questionnaires (Table 3) were completed through face-to-face interviews.

Table 3 Distribution of survey questionnaire

\begin{tabular}{llccc}
\hline Location & Survey Date & Conducted & Completed & Recovery \\
\hline Coking plant, Beijing & 17 May, 2014 & 110 & 105 & $95 \%$ \\
Pesticide factory, Hangzhou & 6-8 June, 2014 & 110 & 103 & $94 \%$ \\
Fertilizer factory, Guangzhou & 14- 15 June, 2014 & 110 & 104 & $95 \%$ \\
Disney project, Shanghai & 15-16 August, 2014 & 110 & 100 & $91 \%$ \\
\hline
\end{tabular}

The data were pooled for model verification as the respective socio demographic characteristics of the four locations were not significantly different. The summary statistics (Table 4) showed that the survey subjects were rather evenly divided between the male and female genders (47.1\% vs. 52.9\%). Collectively, the survey subjects of the four locations averaged 29 years old, 51.9\% had completed high school, and 31.9\% held baccalaureate or higher academic degrees. The majority of the interviewees were gainfully employed (70.2\%) with the remainder being unemployed (7\%), in schools (5.1\%), or in retirement (17.7\%). An average household consisted of 3.71 persons and $56 \%$ of the subjects had resided at their current address for 5 or more years. These were middle-low income neighborhoods, where $67.8 \%$ of the subjects earned less than 5000 yuan RMB per month.

Table 4 Socio-demographical profiles of surveyed subjects

\begin{tabular}{lll}
\hline Variable & Distribution & Percent (\%) \\
\hline Gender & Male & 47.1 \\
& Female & 52.9 \\
Age & $<23$ & 9.7 \\
& $23-35$ & 43.7 \\
& $35-50$ & 24.3 \\
\hline
\end{tabular}




\begin{tabular}{|c|c|c|}
\hline \multirow{6}{*}{ Education } & $>50$ & 22.3 \\
\hline & Primary school & 20.9 \\
\hline & High school & 27.4 \\
\hline & Junior college & 20.4 \\
\hline & Bachelor & 24.5 \\
\hline & Master or above & 6.8 \\
\hline \multirow{6}{*}{$\begin{array}{l}\text { Household } \\
\text { size }\end{array}$} & 1 person & 1.7 \\
\hline & 2 persons & 7.8 \\
\hline & 3 persons & 43.9 \\
\hline & 4 persons & 17.5 \\
\hline & 5 persons & 22.6 \\
\hline & $>5$ persons & 6.6 \\
\hline \multirow[t]{7}{*}{ Occupation } & Unemployed & 7.0 \\
\hline & Student & 5.1 \\
\hline & Freelancer & 10.9 \\
\hline & Worker & 41.3 \\
\hline & Self employed & 4.6 \\
\hline & Professionals & 13.3 \\
\hline & Retiree & 17.7 \\
\hline \multirow{4}{*}{$\begin{array}{l}\text { Income } \\
\text { (RMB }^{*} \text { per } \\
\text { month) }\end{array}$} & $<3,000$ & 33.3 \\
\hline & $3,000-5,000$ & 34.5 \\
\hline & $5,000-8,000$ & 20.9 \\
\hline & $>8,000$ & 11.4 \\
\hline \multirow{5}{*}{$\begin{array}{l}\text { Residence } \\
\text { duration }\end{array}$} & $<1$ years & 16.3 \\
\hline & $1-3$ years & 14.8 \\
\hline & 3-5 years & 12.9 \\
\hline & 5-10 years & 17.7 \\
\hline & >10 years & 38.3 \\
\hline
\end{tabular}

* RMB means Chinese currency, approximately, 6.50 yuan exchange for \$1.00 US

\subsection{Structural equation modeling}

Structural equation modeling (SEM) involved computer algorithms and statistical methods that were used to deduce relationships between unobservable latent variables (i.e. SP, ID, OE, PP, PS, and RE) and observable/measurable factors (i.e. Xi where $i=1,2, \ldots 22$ ) consequently detecting the root causes of the interactions (Santibáñez-Andrade et al., 2015; Xiong et al., 2015). Relationships between latent variables in structural equation modeling can be expressed either by obtaining 
regression equations of measurable variables (i.e. observed data) or by integrating the observed data through linear structural relationships (LISREL) that can be delineated from factor analysis, path analysis, covariance structure modeling, and causal models. In the SEM, the independent variables were categorized into either latent or manifest variables. Latent variables could not be directly observed or measured but might be reflected by manifest variables that were indicators containing objective facts and whose changes were measureable (Xi). The model was developed to describe the hypothetical relationships between latent and manifest variables by examining the variances and co-variances of variables and evaluating the model's goodness of fit based on the experimental data (Wu, 2013; Xiong et al., 2015).

Compared with other methods, SEM had significant advantages in that: (1) it allowed for complex correlations between manifest variables and latent variables beyond simple correlations; (2) it produced error variables to represent unexpected effects that manifest variables could not explain. The general process of Structural equation modeling was applied through iterations of model specifications, model fitting, model assessment, and model modification (Fig. 1), until the hypothetical model had been modified such that the model outcomes matched the experimental data (Levêque and Burns, 2017; Villeneuve et al., 2018). 


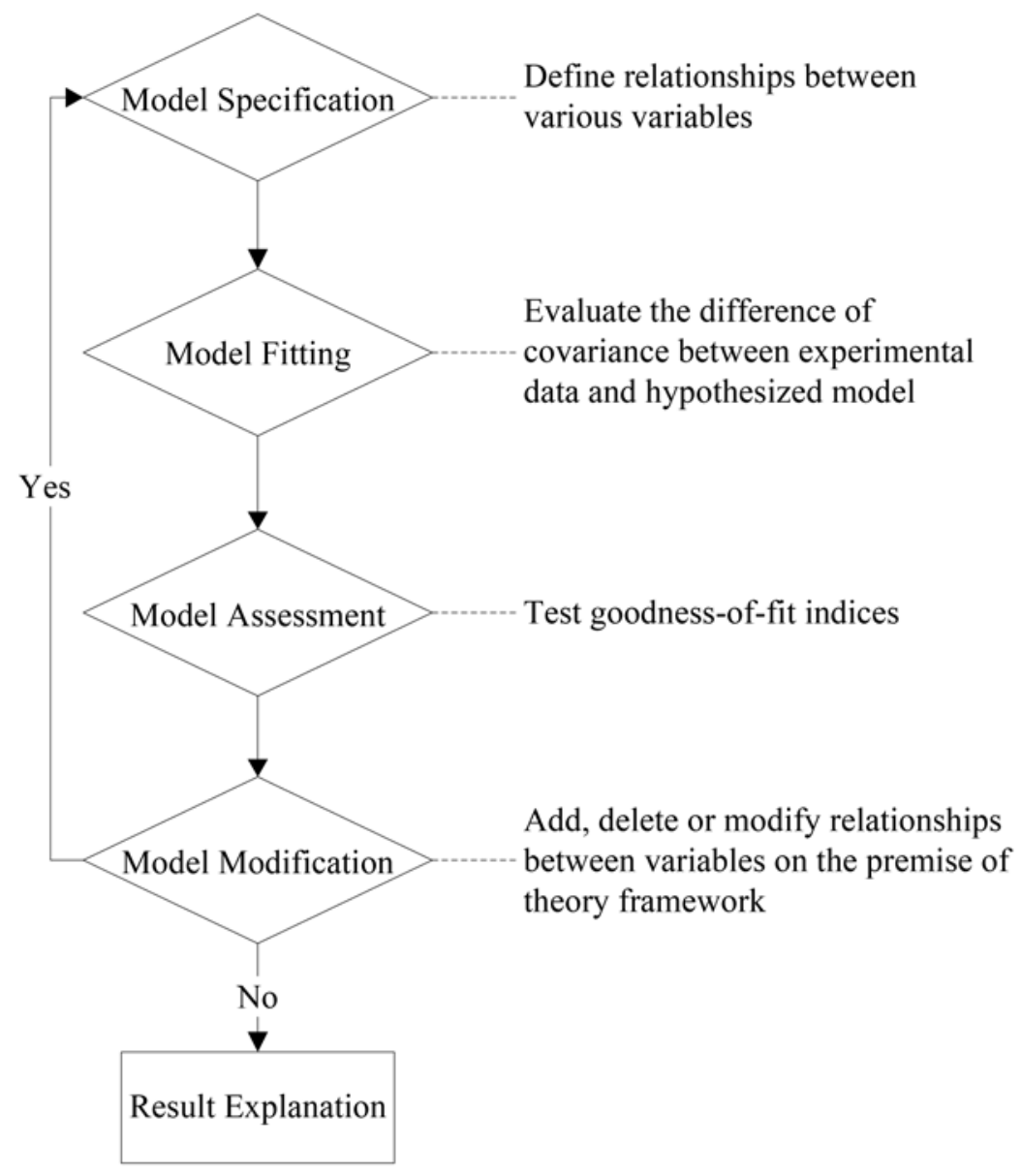

Fig 1. Procedure of establishing the structural equation modeling

(1) Model specification: The SEM contained two components namely the structural and measurement models (Fig. 2). The structural model defined the interrelationships between the latent variables, schematically, Y1, Y2, Y3, ... among which the causes-effects might be unidirectional, and the significance of the reactions were defined, schematically as r13 and r23 in Fig. 2. The two-directional line between Y1 and Y2 denoted that mutual effects were allowed between the latent variables. The measurement model consisted of linear functions that represent the latent variable with a set of manifest variables, i.e. X1 through X6 in Fig. 2. The fact that latent variables might not 
be fully explained by the manifest variables would lead to the corresponding error terms, e1 through e6 and deta 1 through deta 3.

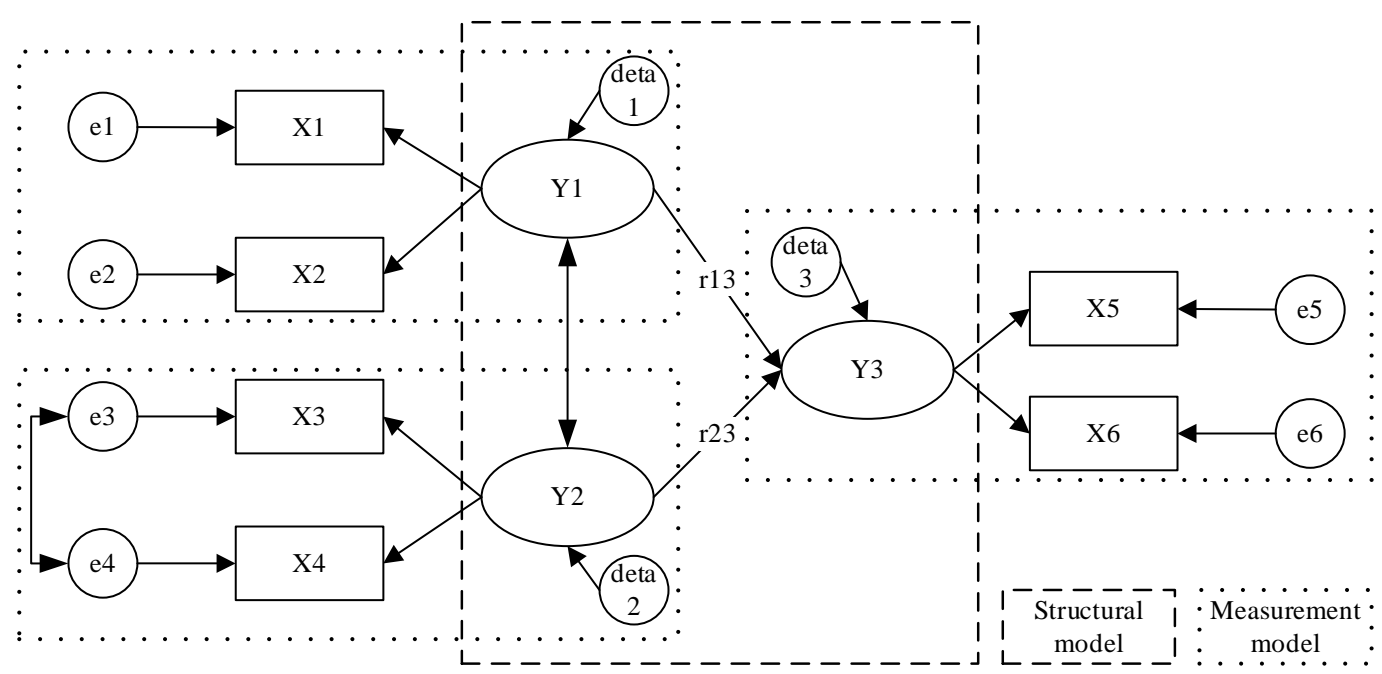

Fig 2. Schematic diagram of structural equation modeling

The SEM model includes a hypothetical structural model (dashed rectangle) of latent variables and their corresponding measurement models (dotted rectangle). The latent variables are depicted by $\mathrm{Y} 1$ and $\mathrm{Y} 2$ (independent) and Y3 (dependent), X1 through X6 depict measured variables, $r$ depict path coefficients, and e1 through e6 depict the error terms for measured variables, while deta 1 through deta 3 depict error terms for latent variables. The single direction arrows depict the direction of the reactions and double directional arrows depict two-way interactions between two variables.

(2) Model fitting: At this stage, partial least square (PLS) techniques and linear structure relationship (LISREL) methods were adopted to maximize the variance explained in either the observed data or outcomes of the model simulation. PLS was applied due to its predictability with small sample sizes, non-normally distributed data, and its exact definition of component scores in conjunction with explaining a large percentage of the variances (Anderson and Gerbing, 1988; Hou et al., 2014a). LISREL was used to optimize the fitting function parameters by establishing a model to estimate fitting functions 
between the covariance of the model and the data, using the Maximum likelihood (ML) method (which allows unbiased, valid, and consistent estimations and accommodates missing values and unlimited non-normally distributed data).

(3) Model assessment: First, the legality of estimation was examined in terms whether there was negative error variance, $>1$ standardized coefficient parameters, and large standard error. Then the covariance in the established model (a priori model) was compared with the covariance of the observed data. Subsequently, goodness-of-fit indices were used to confirm how well the a priori model fitted the observed data. There were several goodness-of-fit indices (GOF) in which the indices associated with the absolute and incremental fit measurements were the most fundamental and informative (Hooper et al., 2008). In this study, the index for absolute fit measurement was the root mean square error of approximation (RMSEA) and the indices of incremental fit measurements included the comparative fit index (CFI), normed-fit index (NFI), and incremental fit index (IFI). These were evaluated to determine if the a priori model was plausible with respect to the data. RMSEA was generally the most preferred criterion and a RMSEA $<0.05$ indicated that the a priori model and the observed data were well fitted. CFI > 0.9 also characterized a well-fitted model. If NFI $>0.9$, the model was sensitive to sample size, and underestimated model fit when samples size was less than 200. Finally, IFI $>0.9$ indicated that the model was acceptable 
(Hooper et al., 2008; Wu, 2013; Xiong et al., 2015).

(4) Model modification: The hypothesized model needed to be modified if GOF indices were not consistent with acceptable thresholds. In this case, relationships between the variables were then added, deleted, or changed according to modification indices (MI). Larger values of MI indicated that there was larger potential for model improvement by changing fixed parameters to free parameters.

\subsection{Hypothetical model}

A hypothetical model showing the latent variables and their interactions was established (Fig. 3) based on information obtained from the literature and from the questionnaire survey investigation. The model included latent variable modules that characterized the influences of information dissemination (ID) and outreach and education (OE), effects of public participation (PP), knowledge of site remediation policy and management (PS), attitudes toward remediation and redevelopment (RE), and understanding of soil pollution (SP) (Fig. 3).

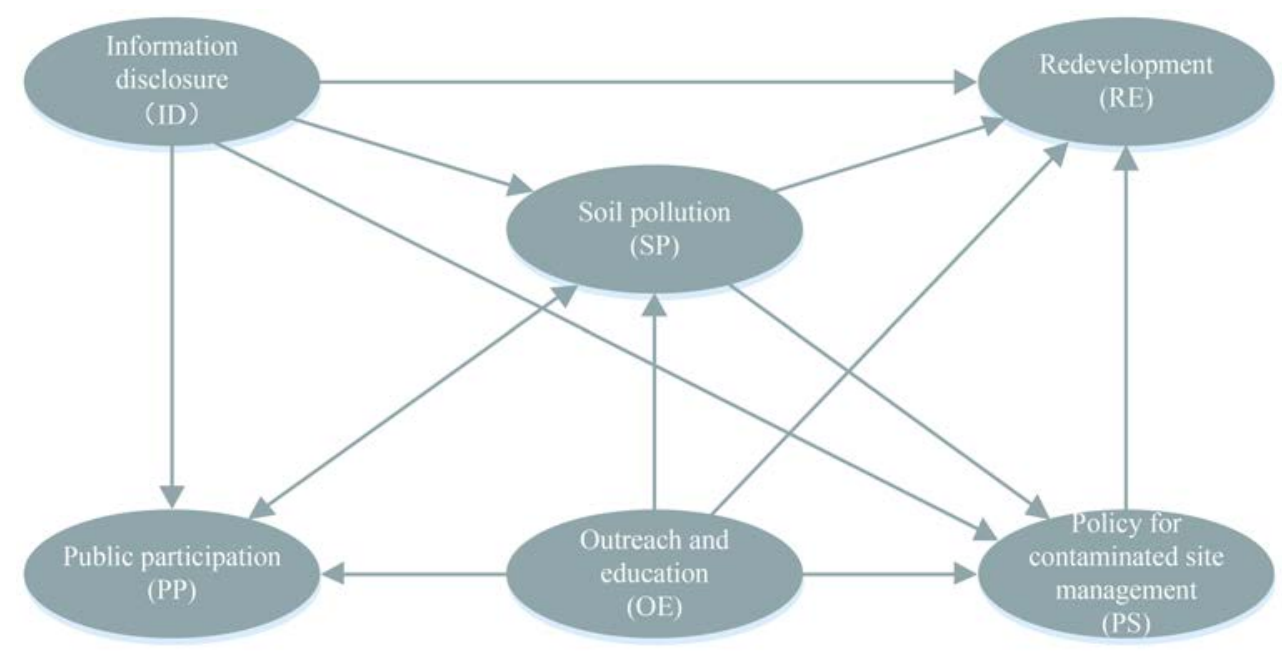

Fig. 3 A proposed model with hypothetical relationships 


\section{Result and discussion}

\subsection{Reduction of latent and manifest variables}

The hypothetical model (Fig. 3) was not entirely in agreement with the observed survey data. The validated model, with optimized goodness of fit (GOF) to the observed data, contained 5 of the original 6 latent variables and their corresponding measurement models retained 12 of the original 22 manifest variables (Fig. 4). The latent variable representing public outreach and public education (OE) was eliminated. Besides the GOF indices (Table 5), the model outcomes provided reasonable explanations of variances in ID, SP, RE, PP and PS. The model predicted that PS and $\mathrm{RE}$ accounted for over $40 \%$ of the variance in the observed data. $84.2 \%$ of the variance of SP was explained by direct and indirect effects of four variables, namely ID, RE, PP and PS. The interactions between latent variables ID, SP, RE, PP and PS were indicated by the path coefficients shown in Fig. 4 and Table 6.

Table 5 Goodness-of-fit indices

\begin{tabular}{lll}
\hline Goodness of Fit Index & Measured & Threshold \\
\hline Root mean square error of approximation (RMSEA) & 0.000 & $<0.05$ \\
Normed-fit index (NFI) & 0.968 & $>0.9$ \\
Comparative fit index (CFI) & 1 & $>0.9$ \\
Incremental fit index (IFI) & 1 & $>0.9$ \\
\hline
\end{tabular}




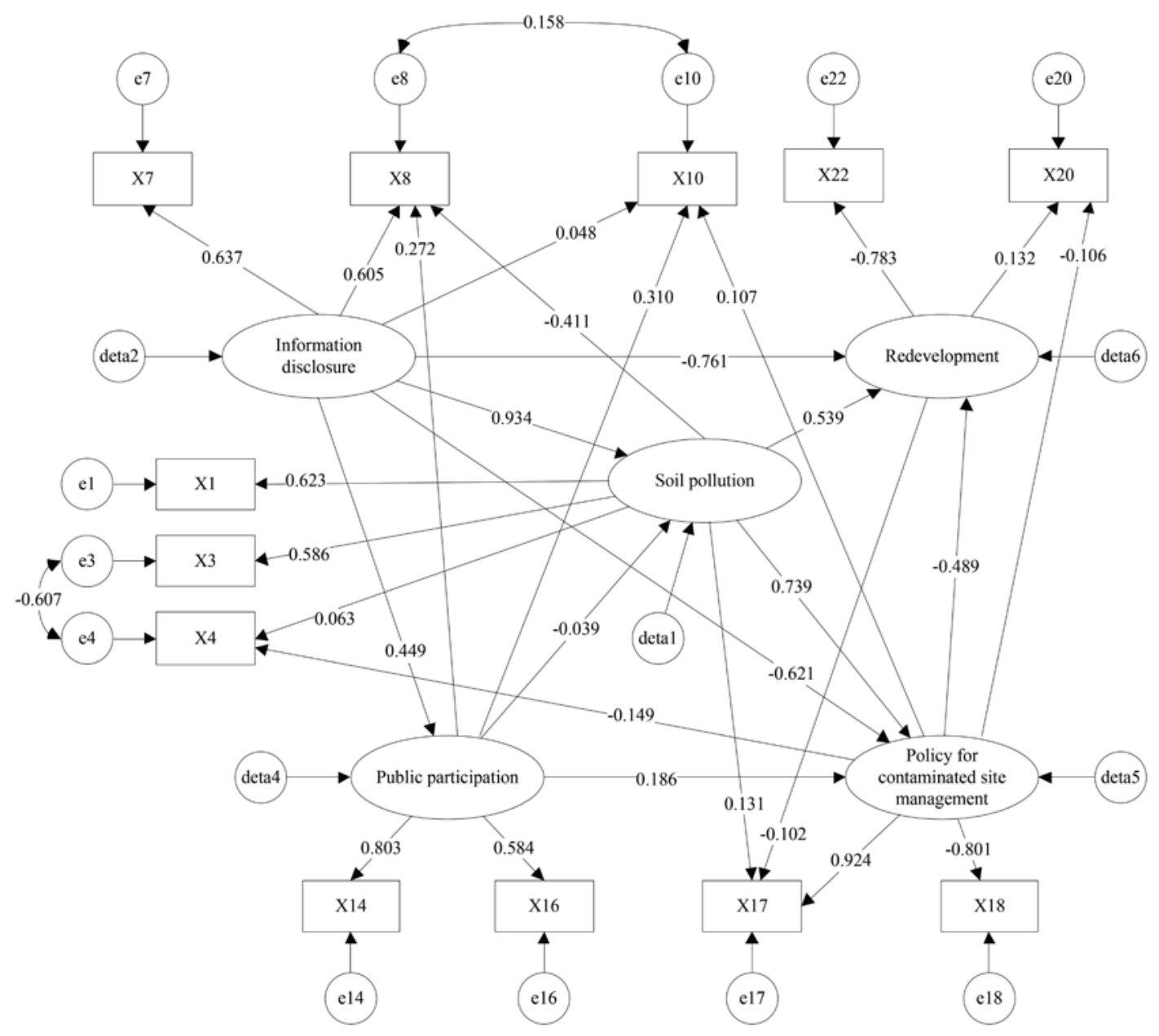

Fig 4. Structural equation modeling of public perception on contaminated site management

\subsection{Interactions between latent variables}

The interactions of SP with PP, ID with RE, and those between OE and other latent variables were rejected in the validation process. Of the originally proposed 12 interactions between latent variables, only 9 appeared in the validated model. Among these, 4 were significant (Table 6). Disseminating accurate information (ID) had significant and positive impacts on both encouraging public participation (PP, $r=$ 0.449 at $\mathrm{p}<0.001)$ and helping the public understand concepts of soil pollution ( $\mathrm{SP}, \mathrm{r}$ $=0.934$ at $\mathrm{p}<0.001)$, while, the effects on site policies (PS) and redevelopment $(\mathrm{RE})$ 
issues were not significant $(r=-0.761$ and -0.621 at $p<0.430$ and $<0.078$, respectively). This indicates that disclosing site information had little impact on understanding of remediation policies, and did not influence (as much as other combinations of factors) willingness to pay and satisfaction with redevelopment.

Active public participation (PP) and knowledge of soil pollution (SP) did significantly affect the familiarity and satisfaction with site remediation policies and management strategies (PS). Public knowledge on the nature of soil pollution (SP) at the relevant site did not, however, significantly impact public participation (PP) and stakeholders' acceptance of outcomes in remediation and redevelopment (RE), yet it exerted significant influence on the other latent factors. Public understanding of the nature and harmful effects of soil pollution (SP) was significantly enhanced by information disclosure (ID) with $\mathrm{r}=0.934$ at $\mathrm{p}<0.001$, and influenced policy and management decisions (PS) with $\mathrm{r}=0.739$ at $\mathrm{p}<0.05$.

Table 6 Interactive relations of latent variables with their path coefficients $(r)$ and levels of significance (p)

\begin{tabular}{|c|c|c|}
\hline Interaction & $\mathrm{r}$ & $\mathrm{p}$ \\
\hline Public participation (PP) $\leftarrow$ Information dissemination (ID) & 0.449 & $* * *$ \\
\hline Soil pollution (SP) $\leftarrow$ Information dissemination (ID) & 0.934 & $* * *$ \\
\hline Soil pollution (SP) $\leftarrow$ Public participation (PP) & -0.039 & 0.569 \\
\hline Site policies (PS) $\leftarrow$ Public participation (PP) & 0.186 & $*$ \\
\hline Site policies (PS) $\leftarrow$ Information dissemination (ID) & -0.621 & 0.078 \\
\hline Site policies (PS) $\leftarrow$ Soil pollution (SP) & 0.739 & * \\
\hline Site redevelopment $(\mathrm{RE}) \leftarrow$ Information dissemination (ID) & -0.761 & 0.430 \\
\hline Site redevelopment $(\mathrm{RE}) \leftarrow$ Soil pollution $(\mathrm{SP})$ & 0.539 & 0.422 \\
\hline Site redevelopment (RE) $\leftarrow$ Site policies (PS) & -0.489 & 0.453 \\
\hline
\end{tabular}




\subsection{Interactions of manifest variables}

The manifest variables that composed the measurement models determined how the not readily quantifiable aspects of public perception were linked to parameters that were observable and measurable through the questionnaire surveys. The validated public perception model outlined in Fig. 4 consisted of five latent variables, whose corresponding measurement models were expressed by a set of manifest variables (Xi) and error terms (ei). Manifest variables X2, X5, X6, X9, X11, X12, X13, X15, X19, and X21 were eliminated during the model validation process. For the remaining manifest variables, 20 latent - manifest variable links were established and 14 of these showed statistically significant relationships (Table 7).

The measurement model of ID was characterized by three manifest variables X7, X8, and X10. The manifest variables X7 $(r=0.637$ at $p<0.001)$ showed that stakeholders paid attention to the information being disclosed, $X 8(r=0.605$ at $p$ $<0.05$ ) indicated that the extent of information disclosure efforts counted strongly and significantly, while X10 exhibited that the credibility of the disseminated information had a weak and non-significant linkage with the effectiveness of information dissemination (ID). 
Table 7 Significant relationships between measurement models and manifest variables

\begin{tabular}{|c|c|c|c|}
\hline Measurement model & Manifest variables & Coefficients (r) & $\mathrm{p}$ \\
\hline \multirow{2}{*}{ ID } & $\mathrm{X} 7$ & 0.637 & $* * *$ \\
\hline & $\mathrm{X} 8$ & 0.605 & $*$ \\
\hline \multirow[t]{3}{*}{$\mathrm{RE}$} & X20 & 0.132 & $* * *$ \\
\hline & $\mathrm{X} 4$ & -0.149 & $*$ \\
\hline & $\mathrm{X} 10$ & 0.107 & $*$ \\
\hline \multirow[t]{3}{*}{ PS } & $\mathrm{X} 17$ & 0.924 & $* * *$ \\
\hline & $\mathrm{X} 18$ & -0.801 & $* * *$ \\
\hline & X20 & -0.106 & $*$ \\
\hline \multirow{2}{*}{ SP } & $\mathrm{X} 1$ & 0.623 & $* * *$ \\
\hline & $\mathrm{X} 3$ & 0.586 & $* * *$ \\
\hline \multirow{4}{*}{ PP } & $\mathrm{X} 8$ & 0.272 & $* *$ \\
\hline & $\mathrm{X} 10$ & 0.310 & $* * *$ \\
\hline & X14 & 0.803 & $* * *$ \\
\hline & $\mathrm{X} 16$ & 0.584 & $* * *$ \\
\hline
\end{tabular}

The public's attitude toward site mitigation and redevelopment (RE) was positively related to their willingness to pay for soil remediation (X20) and negatively affected by the public willingness to purchase properties built on reclaimed sites (X22) and the public understanding of the site policies and management plans (X17). In other words, only stakeholders (i.e. residents) who had confidence on the outcomes of remediation were willing to pay for the remediation and showed willingness to purchase properties built on reclaimed land. Further, the more stakeholders were involved or informed in policy and management of the remediation site, the less likely they would be willing to pay for the cost of remediation and to purchase redeveloped properties. This result apparently contradicts typical expectations that enhanced stakeholder engagement and knowledge sharing reduces project risk and improves wider benefits realization (discussed above), and indicates here that the agencies 
responsible for the remediation failed to win the trust of stakeholders in terms of due processes and anticipated outcomes.

The policies for managing the remediation sites (PS) were affected by five variables. Among them, X17 with $r=0.924$ and X18 with $r=-0.801$ had strongly significant correlations, indicating stakeholder familiarity with site policies (X17) and public dissatisfaction with the remediation policies and management plans (X18). In addition, public participation in policy formulation and site management (PS) would apparently be enhanced if stakeholders were more knowledgeable about soil pollution $(X 4, r=-0.149)$ and the information dissemination was credible $(X 10, r=0.107)$. The public remained skeptical about paying for the cost of remediation (X20, $r=-0.106)$.

Stakeholder understanding of soil pollution (SP) was depicted by five measurable parameters including knowledge of the existence (X1) and causes (X4) of soil pollution, the harmful effects of pollutants (X3), the extent of information dissemination (X8), and familiarity with site policies (X17). Among these parameters, only X1 and X3 exhibited a significant role in promoting public understanding of soil pollution with path coefficients $r=0.623$ and 0.586 , respectively. Those more knowledgeable about soil pollution, from residents residing in the vicinity of seriously affected sites, perceptively were better aware of the potential harmful effects of pollution. In this circumstance, the public would consciously seek information on soil pollution through Internet sources, social media postings, and other transactions if the information disclosure was inadequate. The polluters on the other hand could resist disclosure of pollution information in order to hide the facts from residents for fear of 
the liabilities. This causal relationship may drive the two-way links connecting X3 and X4 with a negative coefficient of -0.607 in Fig. 4.

The influences of public participation (PP) on public perception were driven by the extent of information dissemination (X8), the credibility of the disclosed information (X10), solicitation of public opinions (X14) and satisfaction with the public participation (X16). It demonstrated that, to promote public participation in contaminated site management, the openness in soliciting inputs $(X 14, r=0.803)$ and the public satisfaction with participation $(\mathrm{X} 16, \mathrm{r}=0.584)$ were more important than the extent $(\mathrm{X} 8, \mathrm{r}=0.272)$ and credibility $(\mathrm{X} 10, \mathrm{r}=0.310)$ of the information. However, in these cases the relevant agencies had not provided strong mechanisms for the local public to participate in the contaminated site management / redevelopment process, thus resulting in poor public perception of the remediation projects.

\section{Conclusions}

Public perception of contaminated site management at these four sites is predominantly driven, according to the outcomes of structural equation modeling, by four interacting latent variables, namely the extent of information dissemination, stakeholder knowledge on the extent of soil pollution, expectations of outcomes in site remediation and redevelopment, and public satisfaction with the decision making processes (i.e. site policies and management actions). Among these, information dissemination was the most influential factor. This will directly affect the conduct, and relationships, of other variables. Notably, public perception (in terms of 
satisfaction with the remediation activities) was affected by information dissemination and public knowledge of soil pollution, but not by public participation in the decision-making process. This contradicts to some extent earlier literature which argues that larger complex sites in urban and sub-urban areas with large local populations require more complex stakeholder engagement activities that move beyond merely informing stakeholders to consultation and collaboration (e.g. Cundy et al., 2013). This may be a consequence of the local socio-cultural and political setting and expectations, and highlights the importance of local cultural and other factors in stakeholder perception and optimization of remediation / redevelopment strategies. The ranking of influences on public perception is as follows: [the extent of information dissemination] $>$ [stakeholders’ knowledge on soil pollution] $\approx$ [public satisfaction with the decision making processes] $>$ [expectations of outcomes in site remediation and redevelopment].

The above outlined latent variables are linked to three measurable/observable manifest variables, namely the extent of information disclosure, credibility of information disclosure, and public familiarity with policies. The ranking in terms of their influences is as follows [extent of information disclosure] $\approx$ [credibility of information disclosure] >> [public familiarity with policies]. Responsible agencies therefore should focus on public accessibility to reliable information and encourage public inputs into policies for contaminated site management.

Nonetheless, three aspects should be further focused on in future research. One is that the established model cannot fully explain the variances present in public 
perception as the total underlying mechanisms driving public perception are too complicated to simulate and fully quantify. Second, residents' responses to environmental hazards like contaminated sites may be emotional, which may exacerbate the uncertainties of model validation. Thirdly, this work applies to four specific (although varying context) sites in China. The extent to which the study findings can be translated (i.e. are portable) to other socio-economic, cultural and political settings requires further analysis.

Funding: This work was supported by the National Natural Science Foundation of China [grant number 41173123]. 


\section{References}

Alberini, A., Tonin, S., Turvani, M., 2007. Willingness to pay for contaminated site cleanup policies: evidence from a conjoint choice study in Italy. Rev. d'économie politique, 117(5), 737-749.

Anderson, J.C., Gerbing, D.W., 1988. Structural Equation Modeling in Practice: A Review and Recommended Two-Step Approach. Psychol. Bull. 103 (3), 411-423. DOI: 10.1037/0033-2909.103.3.411.

Bardos, R.P., Cundy, A.B., Smith, J.W.N., Harries, N., 2016. Sustainable remediation. J. Environ. Manage. 184, 1-3. DOI: 10.1016/j.jenvman.2016.10.021.

Blanc, A., Métivier-Pignon, H., Gourdon, R., Rousseaux, P., 2004. Life cycle assessment as a tool for controlling the development of technical activities: application to the remediation of a site contaminated by sulfur. Adv. Environ. Res. 8(3), 613-627. DOI: 10.1016/S1093-0191(03)00034-0.

Busset, G., Sangely, M., Montrejaud-Vignoles, M., Thannberger, L., Sablayrolles, C., 2012. Life cycle assessment of polychlorinated biphenyl contaminated soil remediation processes. Int. J. Life Cycle Assess. 17(3), 325-336. DOI: 10.1007/s11367-011-0366-7.

Cadotte, M., Deschênes, L., Samson, R., 2007. Selection of a remediation scenario for a diesel-contaminated site using LCA. Int. J. Life Cycle Assess. 12(4), 239-251. DOI: 10.1065/lca2007.05.328.

Cappuyns, V., 2013. Environmental impacts of soil remediation activities: quantitative and qualitative tools applied on three case studies. J. Clean. Prod. 52(1), 145-154. 
DOI: 10.1016/ j.jclepro.2013.03.023.

Cappuyns, V., 2016. Inclusion of social indicators in decision support tools for the selection of sustainable site remediation options. J. Environ. Manage. 184, 45-56. DOI: 10.1016/j.jenvman.2016.07.035.

Carpita, M., Ciavolino, E., 2014. MEM and SEM in the GME Framework: Statistical Modeling of Perception and Satisfaction. Procedia Econ. Financ. 17, 20-29. DOI: 10.1016/S2212-5671(14)00874-0.

Contaminated Land Rehabilitation Network for Environmental Technologies (CLARINET), 2002. Sustainable Management of Contaminated Land: An Overview.

\section{http://www.commonforum.eu/Documents/DOC/Clarinet/rblm_report.pdf}

(accessed 16.04.20).

Cundy, A.B., Bardos, R.P., Church, A., Puschenreiter, M., Friesl-Hanl, W., Müller, I., Neu, S., Mench, M., Witters, N., Vangronsveld, J., 2013. Developing principles of sustainability and stakeholder engagement for "gentle" remediation approaches: The European context. J. Environ. Manage. 129(15), 283-291. DOI: 10.1016/j.jenvman.2013.07.032.

Eisenhauer, N., Bowker, M.A., Grace, J.B., Powell, J.R., 2015. From patterns to causal understanding: Structural Equation Modeling (SEM) in soil ecology. Pedobiologia 58(2-3), 65-72. DOI: 10.1016/j.pedobi.2015.03.002.

Eiser, J.R., Stafford, T., Henneberry, J., Catney, P., 2009. “Trust me, I’m a Scientist (Not a Developer)": Perceived Expertise and Motives as Predictors of Trust in 
Assessment of Risk from Contaminated Land. Risk Anal. 29(2), 288-297. DOI: 10.1111/j.1539-6924.2008.01131.x.

Feldman, D.L., Hanahan, R.A., 1996. Public Perceptions of a Radioactively Contaminated Site: Concerns, Remediation Preferences, and Desired Involvement. Environ. Health Persp. 104(12), 1344-1352.

Ferguson, C.C., 1999. Assessing risks from contaminated sites: policy and practice in 16 European countries. Land Contam. Reclam. 7(2), 33-54.

Grasmück, D., Scholz, R.W., 2005. Risk perception of heavy metal soil contamination by high exposed and low-exposed inhabitants: The role of knowledge and emotional concerns. Risk Anal. 25(3), 611-622.

Greenberg, M., Lewis, M.J., 2000. Brownfields Redevelopment, Preferences and Public Involvement: A Case Study of an Ethnically Mixed Neighborhood. Urban Stud. 37(13), 2501-2514. DOI: 10.1080/00420980020080661.

Harclerode, M.A., Lal, P., Vedwan, N., Wolde, B., Miller, M.E., 2016. Evaluation of the role of risk perception in stakeholder engagement to prevent lead exposure in an urban setting. J. Environ. Manage. 184, 132-142. DOI: 10.1016/j.jenvman.2016.07.045.

Hooper, D., Coughlan, J., Mullen, M., 2008. Structural Equation Modelling: Guidelines for Determining Model Fit. Electronic J. Bus. Res. Method. 6(1), 53-60.

Hou, D.Y., Al-Tabbaa, A., Chen, H.Q., Mamic, I., 2014a. Factor analysis and structural equation modeling of sustainable behavior in contaminated land 
remediation. $\quad$ J. $\quad$ Clean. $\quad$ Prod. $84 \quad$ (1), 439-449. DOI: 10.1016/j.jclepro.2014.01.054.

Hou, D.Y., Al-Tabbaa, A., Guthrie, P., Hellings, J., Gu, Q.B., 2014b. Using a hybrid LCA method to evaluate the sustainability of sediment remediation at the London Olympic Park. J. Clean. Prod. 83(15), 87-95. DOI: 10.1016/j.jclepro.2014.07.062.

Jin, L., 2012. Legislation research on prevention and control of China soil pollution. M.L. thesis, Department of Law, Jilin University, Jilin, China.

Johansson, M.V., Forslund, J., Johansson, P., Samakovlis, E., 2011. Can we buy time? Evaluation of the Swedish government's grant to remediation of contaminated sites. J. Environ. Manage. 92(4), 1303-1313. DOI: 10.1016/j.jenvman.2010.12.017.

Ko, D.W., Stewart, W.P., 2002. A structural equation model of residents’ attitudes for tourism development. Tourism Manage. 23(5), 21-530. DOI: 10.1016/S0261-5177(02)00006-7.

Levêque, J.G., Burns, R.C., 2017. A Structural Equation Modeling approach to water quality perceptions. J. Environ. Manage. 197, 440-447. DOI: https://doi.org/10.1016/j.jenvman.2017.04.024.

Li, X.N., Jiao, W.T., Xiao, R.B., Chen, W.P., Bai, Y.Y., 2016. Regional Variations of Public Perception on Contaminated Industrial Sites in China and Its Influencing Factors. Int. J. Environ. Res. Public Health 13(4), 410-425. DOI: 10.3390/ijerph13040410. 
Li, Y.Y., Tan, S.K., 2012. Cognition of Residents and Influencing Factors around Wuhan. China Real Estate 2, 29-37.

Regeneration of European Sites in Cities and Urban Environments (RESCUE), 2005. Best practice guidance for sustainable Brownfield regeneration. Land Quality Press, a Division of Land Quality Management Ltd. ISBN 0-9547474-0-2.

REVIT, 2007. Working towards more effective and sustainable brownfield revitalisation policies. Stakeholder Engagement a Toolkit. http://www.revit-nweurope.org/selfguidingtrail/27_Stakeholder_engagement_a_t oolkit-2.pdf. (accessed 17.05.15).

Rodrigues, S.M., Pereira, M.E., da Silva, E.F., Hursthouse, A.S., Duarte, A.C., 2009a. A review of regulatory decisions for environmental protection: part I-challenges in the implementation of national soil policies. Environ. Int. 35(1), 202-213. DOI: 10.1016/j.envint.2008.08.007.

Rodrigues, S.M., Pereira, M.E., da Silva, E.F., Hursthouse, A.S., Duarte, A.C., 2009b. A review of regulatory decisions for environmental protection: part II-the case-study of contaminated land management in Portugal. Environ. Int. 35(1), 214-225. DOI: 10.1016/j.envint.2008.08.012.

Santibáñez-Andrade, G., Castillo-Argüero, S., Vega-Peña, E.V., Lindig-Cisneros, R., Zavala-Hurtado, J.A., 2015. Structural equation modeling as a tool to develop conservation strategies using environmental indicators: The case of the forests of the Magdalena river basin in Mexico City. Ecol. Indic. 54, 124-136. DOI:10.1016/j.ecolind.2015.02.022. 
Scholz, R.W., Siegrist, M., 2010. Low Risks, High Public Concern? The Cases of Persistent Organic Pollutants (POPs), Heavy Metals, and Nanotech Particles. Hum. Ecol. Risk Assess. 16(1), 185-198. DOI: 10.1080/10807030903459114.

Smith, J., 2010. A Framework for Assessing the Sustainability of Soil and Groundwater Remediation. CL:AIRE, London, ISBN: 978-1-905046-19-5.

Sousa, C.D., 2001. Contaminated sites: the Canadian situation in an international context. J. Environ. Manage. 62(2), 131-154. DOI: 10.1006/jema.2001.0431.

SU BRIM Project, 2008. Community Engagement, Urban Regeneration, and Sustainability. SUBR: IM bulletin 8 (SUB 8). http://www.claire.co.uk (accessed 17.05.15).

Subramanian, N., Gunasekaran, A., Yu, J., Cheng, J., Ning, K., 2014. Customer satisfaction and competitiveness in the Chinese E-retailing: Structural equation modeling (SEM) approach to identify the role of quality factors. Expert Syst. Appl. 41(1), 69-80. DOI:10.1016/j.eswa.2013.07.012.

Swartjes, F.A., Rutgers, M., Lijzen, J.P.A., Janssen, P.J.C.M., Otte, P.F., Wintersen, A., Brand, E., Posthuma, L., 2012. State of the art of contaminated site management in the Netherlands: policy framework and risk assessment tools. Sci. Total Environ. 427-428, 1-10. DOI: 10.1016/j.scitotenv.2012.02.078.

Thornton, G., Franz, M., Edwards, D., Pahlen, G., Nathanail, P., 2007. The challenge of sustainability: incentives for brownfield regeneration in Europe. Environ. Sci. Policy, 10(2), 116-134. DOI: 10.1016/j.envsci.2006.08.008.

Tonin, S., Turvani, M., Alberini, A., 2011. Knowledge about, importance of, and 
attitudes towards industrial brownfield reuse. Sci. Region. 10(3), 97-126.

Trzeciakowski, J.P., Gardiner, L., Parrish, A.R., 2014. Effects of environmental levels of cadmium, lead and mercury on human renal function evaluated by structural equation modeling. Toxicol. Lett. 228(1), 34-41. DOI: 10.1016/j.toxlet.2014.04.006.

United States Environmental Protection Agency (USEPA), 2008. Green Remediation: Incorporating Sustainable Environmental Practices into Remediation of Contaminated Sites. EPA 542-R-08-002. Washington, DC.

Vandermoere, F., 2008. Hazard Perception, Risk Perception, and the Need for Decontamination by Residents Exposed to Soil Pollution: The Role of Sustainability and the Limits of Expert Knowledge. Risk Anal. 28(2), 387-398. DOI: 10.1111/j.1539-6924.2008.01025.x.

Villeneuve, B., Piffady, J., Valette, L., Souchon, Y., Usseglio-Polatera, P., 2018. Direct and indirect effects of multiple stressors on stream invertebrates across watershed, reach and site scales: A structural equation modelling better informing on hydromorphological impacts. Sci. Total Environ. 612, 660-671. DOI: https://doi.org/10.1016/j.scitotenv.2017.08.197.

Volkwein, S., Hurtig, H.W., Klopffer, W., 1999. Life cycle assessment of contaminated sites remediation. Int. J. Life Cycle Assess. 4(5), 263-274. DOI: 10.1007/BF02979178.

Wu, M.L., 2013. Structure Equation Modeling-Operation and Application of AMOS. Chongqing University Press, Chongqing. 
Xiong, B., Skitmore, M., Xia, B., 2015. A critical review of structural equation modeling applications in construction research. Automat. Constr. 49 (Part A), 59-70. DOI: 10.1016/j.autcon.2014.09.006. 